\title{
Émile Zola aux racines des valeurs européennes, a cura di Marina Geat
}

\section{Maria Emanuela Raffi}

\section{Q OpenEdition \\ 1 Journals}

\section{Edizione digitale}

URL: http://journals.openedition.org/studifrancesi/6068

DOI: 10.4000/studifrancesi.6068

ISSN: 2421-5856

\section{Editore}

Rosenberg \& Sellier

\section{Edizione cartacea}

Data di pubblicazione: 1 mai 2011

Paginazione: 205

ISSN: 0039-2944

\section{Notizia bibliografica digitale}

Maria Emanuela Raffi, «Émile Zola aux racines des valeurs européennes, a cura di Marina Geat», Studi Francesi [Online], 163 (LV | I) | 2011, online dal 30 novembre 2015, consultato il 13 janvier 2021. URL: http://journals.openedition.org/studifrancesi/6068 ; DOI: https://doi.org/10.4000/studifrancesi.6068

Questo documento è stato generato automaticamente il 13 janvier 2021.

\section{(c) $(1) \odot \odot$}

Studi Francesi è distribuita con Licenza Creative Commons Attribuzione - Non commerciale - Non opere derivate 4.0 Internazionale. 


\title{
Émile Zola aux racines des valeurs européennes, a cura di Marina Geat
}

\author{
Maria Emanuela Raffi
}

\section{NOTIZIA}

AA. VV., Émile Zola aux racines des valeurs européennes, a cura di Marina GEAT, Roma, Anicia, 2010, pp. 127.

1 I contributi di specialisti zoliani raccolti in questo breve volume, prodotto di un convegno organizzato da Marina Geat a Roma in occasione del centenario del trasferimento delle ceneri di Zola al Panthéon (2008), mostrano un profilo particolare dell'autore dei Rougon-Macquart, messo qui in relazione con il formarsi di una coscienza culturale europea. Dopo la presentazione di Francesco MATTEI, l'Introduction di Marina GEAT pone il problema della funzione della letteratura nel mondo contemporaneo, prendendo come punti di riferimento Paul Ricœur, Tzvetan Todorov e Edgard Morin e collocando l'idea di Europa nel punto di incontro dei diversi saperi che essi rappresentano e dei 'mots-valeurs' di cui sono portavoce. Per molti versi anche l'opera di Zola sembra porsi domande analoghe sul senso dell'esistenza e sulla coesistenza di 'valori' individuali e sociali e si può quindi giustamente ipotizzare che abbia contribuito «à l'ouverture des consciences à l'avenir». Entrando nel vivo del problema con Littératures et valeurs (pp.27-38), Philippe HAMON propone anzitutto una definizione molto articolata del concetto di 'valeur' in quattro punti, che mostrano certamente la sua importanza, ma anche la relatività e la variabilità del livello cui tale concetto si colloca. Per quanto riguarda Zola in particolare, Hamon mette in luce l'esemplarità della sua attività in quanto scrittore europeo - per origini e diffusione dell'opera -, ostile a prese di posizione nazionalistiche, sostenitore di nuove forme d'arte e conflittuale anche nella scelta dello stile di scrittura. Alain PAGÈs prende in esame, nel saggio successivo (La panthéonisation d'Émile Zola. Les enjeux d'un hommage républicain, pp. 39-58) le ragioni ( 'valeurs') che hanno motivato o reso problematica, fra il 1906 e il 
1908, la collocazione di Zola al Panthéon. Particolarmente interessanti appaiono la riproduzione e il commento, proposti da Pagès, delle illustrazioni caricaturali prodotte dai nemici della 'panthéonisation' in varie riviste nel 1908, traccia concreta di un dibattito in cui si fronteggiano alcuni dissidi profondi anche dell'Europa di oggi. In Zola écrivain $d u$ XXI $^{e}$ siècle (pp.59-91), Giovanni DoтоLI pone il problema dell'attualità dell'opera di Zola, di cui sottolinea la passione per la scienza e la tecnologia, per le 'expositions universelles', per l'architettura della modernità. Proprio questi elementi, tradotti dalla scrittura zoliana nel mito della scienza e della macchina, nella centralità del lavoro, nel progresso sociale, nell'impegno politico per un 'socialisme de cœur' che sconfina nell'utopia, costituiscono per l'A. il fondamento della modernità di Zola. Marina GEAT propone, a conclusione dell'incontro, una riflessione sulla 'désunion européenne', mettendo in parallelo la Débâcle di Zola e i Mémoires di Jean Monnet sui primi passi dell'unione europea (La tragédie de la désunion: de la "Débâcle" d'Émile Zola aux "Mémoires" de Jean Monnet, pp.93-108). Ne emerge, in tempi e contesti diversi, la comune opposizione al 'nationalisme intolérant' e la condivisione di valori fondamentali che l'A. identifica in tre parole chiave «la terre, la France, l'humanité», tutti e tre riuniti da «une valeur supérieure, celle de l'union».

2 In Appendice, Lucia PERREMUTo presenta in L'affaire Dreyfus: voix d'Italie (pp. 109-121) una serie di documenti che attestano le reazioni (lettere e articoli) di esponenti della cultura italiana al caso Dreyfus e il loro sostegno a Zola fra il 1897 e il 1898. 